\title{
The effect of a workshop on Egyptian nurse educators' motivation and attitude toward evidence based teaching
}

\author{
Farida Mahmoud Hassona ${ }^{1}$, Chris Winkelman ${ }^{2}$, Sahar Hamdy El-Sayed ${ }^{3}$ \\ 1. Nursing Administration, Zagazig University, Egypt. 2. Frances Payne Bolton School of Nursing, case western reserve \\ university, USA. 3. Nursing Administration, Faculty of Nursing, Zagazig University, Egypt
}

Correspondence: Farida Mahmoud Hassona. Address: Nursing Administration, Zagazig University, Egypt. Email: faridahassona@yahoo.com.

Received: November 18, 2012

Accepted: December 9, 2012

Online Published: March 27, 2013

DOI : 10.5430/jnep.v3n10p64

URL: http://dx.doi.org/10.5430/jnep.v3n10p64

\section{Abstract}

Background: Motivations and attitude are known to influence goal directed activity such as adoption of new behaviors in teaching. Accordingly, understanding nurse educators' motivation and attitudes toward evidence-based teaching is a critical step to successfully transforming the faculty's culture to use best practices in nursing education. The aim of this study was to examine the effect of workshop, on Egyptian nurse educators' motivation and attitude toward evidence-based teaching over time.

Methods: Quasi-experimental design with three periods of data collection: a pre-test and two post-test periods at the School of Nursing, Zagazig University, Egypt. A convenience sample of nurse faculties who were invited to attend a one-day workshop was used. There were no exclusion criteria. Four tools were used: the Demographic form, the Follow-up form, The Situational Motivation Scale (SIMS), and the Evidence-Based Nursing Attitude Questionnaire (EBNAQ).

Results: A total of 48 nurse faculty agreed to participate in the study; they were female with a mean age of 30 years and an average of 5.5 years of experience in academic setting. Half of the participants had master's degree or higher. There were significant differences between the pre-, post- and follow-up scores in three of the motivation subscales. Regarding "lack of motivation", these scores and scores of attitude toward evidence based teaching did not change over time. There was a significant difference in the external regulation score comparing faculty subgroups (i.e., implementers versus nonimplementers).

Conclusions: A workshop about best practices in nursing education fostered increased intrinsic motivation, identified regulation, and external regulation immediately and changes were sustained over a three month period. A total of $23 \%$ of workshop participants implemented an evidence-based education strategy after the workshop, promoting best practices in nursing education.

\section{Key words}

Motivation, Attitude, Evidence-based teaching, Egyptian educators 


\section{I ntroduction}

Achieving excellence in nursing education requires evidence-based curricula, teaching approaches, and evaluation methods ${ }^{[1]}$. Just as nurse educators need to be familiar with evidence for clinical practice, they must also apply evidence in teaching and learning ${ }^{[2]}$. It is challenging to identify and use research about education in nursing curricula ${ }^{[2,3]}$. Nonetheless, knowledge about for evidence-based teaching is essential for nursing faculty ${ }^{[4,5]}$.

Little is known about what factors influence the incorporation of evidence in classroom and clinical teaching by nurse educators. Two factors, motivations and attitude-are known to influence goal directed activity such as adoption of new behaviors in teaching ${ }^{[6]}$. Understanding nurse educators' motivation and attitudes toward evidence-based teaching is a critical step to successfully transforming the faculty's culture to use best practices in nursing education ${ }^{[7]}$.

This is a report of a project that examined the effects of workshop, "Best Practices in Nursing Education," on Egyptian nurse educators' motivation and attitude toward evidence-based teaching over time. The associations between motivation and attitude with the incorporation of evidence-based teaching subsequent to the workshop were also examined. The research questions were:

1) Is there a difference in motivation or attitude toward evidence-based teaching among workshop participants over time, compared values obtained before, immediately following and three months following the workshop?

2) Is there a difference between motivation or attitude at follow-up among faculty who implement goal for incorporating an evidence-based strategy for teaching compared to faculty who do not implement a goal?

\section{Background}

Teaching strategies must empower nursing students to develop habits of thinking based on evidence for making patientcentered clinical judgments ${ }^{[8,9]}$. Educators who implement strategies that are effective have some measure of assurance that they will be able to achieve consistent learning outcomes ${ }^{[10]}$. Habits of thinking based on evidence are advocated in clinical settings to make patient-centered judgments. Similarly, among faculty, habits of thinking based on evidence in education may help student-centered teaching ${ }^{[4]}$.

Nurse educators need pedagogical skills as well as clinical skills ${ }^{[1,8,11]}$. Resources such as time and access to data-based publications can foster the integration of evidence-based pedagogical skills. Professional development is recommended to help nurse educators adopt effective practices in teaching and learning ${ }^{[9,12]}$. Personal factors may also influence to adoption of evidence-based teaching strategies by nurse educators. The Theory of Planned Behavior suggest that both motivation and attitude influence adoption of learned material ${ }^{[13,14]}$. To date, there is limited information about how motivation and attitudes influence nursing educator behaviors outside of the United States ${ }^{[15]}$.

In the Theory of Planned Behavior, attitude toward the behavior is defined as the individual's positive or negative feelings about performing a behavior ${ }^{[16]}$. Faculty attitudes toward the evidence in teaching and learning may facilitate or hinder adoption of best practices ${ }^{[14]}$. It is reasonable to posit that nurse educators with a positive attitude toward evidence-based practices in nursing education would implement behaviors congruent with best practices.

Motivation has been identified as a critical factor affecting faculty behavior ${ }^{[13,17,18]}$. Several approaches have been developed to explain motivation and one of the most common in educational research is self-determination model $(\mathrm{SDT})^{[19,20]}$. Refinement of this theory proposes there are four components of motivation: intrinsic, external regulation, self-regulation, and a motivation. These components are detailed in Box1.

Faculty of Nursing at Zagazig University share in the Continuous Improvement and Qualified Accreditation Project (CIQAP). Standards for this project require nurse educators to review and update programs of nursing, develop 
educational objectives, and use innovative teaching methods that focus on use of evidence in the teaching of nursing in order to help students to broaden thinking and involving them in the learning process.

The authors undertook to develop a workshop for nurse educators about best practices in nursing education to help meet CIQAP standards. Curiosity about whether personal factors of motivation and attitude would influence adoption of evidence-based teaching strategies by attendees motivated the authors to develop a research project to extend information about motivation and attitudes of nurse educators and adoption of evidence-based practices in nursing education over time.

\section{Methods}

\subsection{Research design}

The study used a quasi-experimental design with survey-style paper questionnaires. There were three periods of data collection: a pre-test and two post-test periods. One post-test period immediately followed the workshop and the second occurred three months after the workshop.

\subsection{Ethical considerations}

The study received approval from an affiliated University Institutional Review Board. Informed consent was waived since no personally identifiable information was obtained. The Dean of Faculty of Nursing- Zagazig University also provided permission to conduct the study.

\subsection{Setting}

The study was conducted at the School of Nursing, Zagazig University, Egypt. Zagazig University was founded in 1974 as a state university to create and transfer knowledge that will shape citizens who contribute to their communities and lead their professions in a global society (www.zu.edu). The School of Nursing consists of six academic departments: Nursing Administration, Community Health Nursing, Pediatric Nursing, Medical Surgical Nursing, Psychiatric and Mental Health Nursing, and Obstetric and Gynecological Nursing. Over 1200 undergraduate students are currently enrolled in the four year nursing program.

\subsection{Sample}

A convenience sample of nurse faculties from Zagazig and from regional nursing programs who were invited to attend a one-day workshop titled "Best Practices in Nursing Education was used. There were no exclusion criteria. On-site registration was required.

\subsection{Instruments}

Four tools were used in this study: the Demographic form, the Follow-up form, The Situational Motivation Scale (SIMS), and the Evidence-Based Nursing Attitude Questionnaire (EBNAQ). The demographic form was investigator-developed and collected age, education, academic rank, specialty in faculty post, and years of experience as both an educator and clinician. A second investigator-designed tool, the Follow-up form, asked participants at three months after the workshop if they were working towards achieving a goal of implementing an evidence-based strategy formulated during the workshop and, if not working towards goal implementation, what barriers they perceived related to goal attainment.

The SIMS developed by Guay and colleagues ${ }^{[21]}$ to measure the motivation of nurse educators. There is no overall score of motivation; instead each type of motivation is measured, congruent with theoretical descriptions of motivation ${ }^{[19,20]}$. The scale consists of 16 items grouped under four subscales: (1) intrinsic motivation, (2) identified regulation, (3) external regulation, and (4) amotivation. Each item has a 7-point Likert scale ranging from 1 (not all) to 7 (exactly). Each subscale has a range of 4-28 with a high score indicating that the attribute is highly present. Internal consistency, using Cronbach's 
alpha, for the SIMS subscales are reported as follows: intrinsic motivation at .95; self-identified regulation at .85; external regulation at .62; and amotivation at $.83^{[21]}$.

The EBNAQ was developed to measure attitudes of nurses toward evidence-based practice ${ }^{[22]}$. The Principal Investigator modified the survey by replacing the phrase "evidence-based nursing" with "evidence-based teaching in nursing" to improve congruence with the workshop's purpose. The questionnaire has 15 items. Participants use a 5-point Likert scale to respond, with 1 indicating strongly disagree and 5 indicting strongly agree. The internal consistency for the EBNAQ before modification was reported at $.85^{[22]}$. The maximum score obtainable is 75 with a higher score indicating a positive attitude toward evidence-based teaching in nursing. Before data collection, content validity of the tools for our proposed sample was established by asking five faculty members at the Zagazig University School of Nursing to evaluate them using a structured form that asked about readability, clarity, congruence with the definitions of the constructs (i.e., motivation and attitude) and acceptability. The faculty is fairly fluent in English as a job requirement; course content and related material are delivered in English. Their comments, generally around selection of vocabulary and sentence construction, were used to revise the forms. Next, the survey style tools were administered as a pilot to five different School of Nursing faculty members and asked for feedback; no further modification was suggested. As these five faculty members attended the workshop subsequently, these data were incorporated in our study.

\subsection{Data collection}

On the day of the workshop, registrants received two envelopes. The first envelope had the cover letter explaining the purpose of the study, what participation would entail, and the survey style questionnaires. Envelopes were consecutively numbered and participants were instructed in the cover letter to return all questionnaires (i.e., the demographic form, the SIMS, and the EBNAQ) in the numbered envelope and hold the second envelope until the workshop ended. There were 30 minutes between registration and the beginning of the workshop, sufficient time to complete the surveys which took 15 minutes to complete in our pilot. The second envelope contained the SIMS, EBNAQ, the Follow-up form to detail the goal for adopting an evidence-based strategy only (other fields were left blank), and a request for re-contact information. Participants were instructed to complete the surveys in the second envelope at the end of the workshop or, if not convenient, in the next 24 hours and return them to the Principal Investigator whose contact information was in the cover letter. Linking information was collected as outlined in the cover letter when attendees turned in second envelopes. When contact information was provided, the follow-up form was given to the participant three months after workshop attendance for completion. It was not necessary to undertake to complete the follow-up form to be a participant.

\subsection{I ntervention}

The intervention was a workshop titled "Best Practices in Nursing Education". A month before the workshop, information was distributed to faculty at the Zagazig School of Nursing and nearby schools of nursing. The workshop was in English, a shared language in Egypt where regional Arabic language dialects can make oral communication challenging. Content about research in education was delivered as a lecture and activities to develop habits of thinking about evidenced-based practice were delivered when participants broke into small groups designated by their teaching specialty (pediatrics, obstetrics, and so on). The four small group activities were (1) formulating a practice question, using the PatientIntervention-Comparison-Outcome ( PICO) format ${ }^{[23]}$, listing as many sources of empiric research as possible and then discussing how to integrate evidence with clinical expertise and patient preferences; (2) transitioning from clinical thinking to educational thinking during which members in each group was asked to list at least one effective educational strategy already used, based on content presented in the morning and then explain to each other how the strategy is effective drawing on research, expertise, and student/ contextual factors that are components of evidence-based practice; (3) describing the use of simulation and applying evidence-based practices to that situation to achieve a desired outcome (i.e., applying the PICO format); and (4) asking each group to generate goals to apply content in a course or setting. The workshop teaching aids included power point slides, flip charts, and handouts, a reference list of sources cited in the workshop, and sources for additional content. After the last activity, content was summarized by the speaker along with the outcome of the activities. Participants were invited participants to stay and complete the immediate post-workshop 
surveys. The plan for follow-up in three months was explained verbally. Email was used to remind participants at eight weeks after the workshop that a follow-up survey would be sent in four weeks, giving them ability to opt out. At 12 weeks after the workshop, surveys were sent via email and, for local faculty, delivered directly by hand. For those who did not send back the surveys, a second email or personal contact was used in re-contacting participants. It is not common in Egypt to collect data via the internet, hence our reliance on the paper-and-pencil format.

\subsection{Data analysis}

Scores for each subscale of the SIMS and for the total EBNAQ were calculated for each participant and treated as continuous variables in the analysis. Continuous variables were summarized by means with standard deviations and categorical variables were summarized by frequencies. Repeated measures analysis of variance (RM-ANOVA) was used to answer the first research question. Paired independent sample t-tests were used to answer the second research question. The statistical package for social sciences (SPSS) version 17 software was used to build a database and for all analyses. An alpha of .05 was selected as significant. Data were examined for violations of assumptions for each of the statistical models used ${ }^{[24]}$.

\section{Results}

\subsection{Sample}

Fifty nurse educators attended the workshop and 48 agreed to participate at times 1 and 2, yielding a consent rate of $96 \%$. At time 3, three months after the workshop, 40 participants returned completed surveys, yielding a consent rate of $80 \%$. Forty-one participants were from Zagazig University; three were from Fayoum and Damanhur each, and one from Helwan Universities. Table 1 summarizes demographic characteristics of the sample. The most common academic rank was demonstrator with 24 participants. The typical study participant was about 30 years old, worked in an academic setting for 5.5 years and worked in a hospital for an average of two years. Half of the participants had a master's degree or higher. Participants were fairly evenly distributed between the specialties of nursing common in Universities in Egypt with the highest number in Medical-Surgical nursing (22.9\%) and the lowest number in pediatrics (8.3\%).

\subsection{Differences in motivation and attitude over time}

Table 2 shows the mean scores of each motivation subscale and the attitude scores at each data collection time point. The last two columns detail the results of analyzing differences in scores over time (i.e., RM-ANOVA F and $p$ values). There were significant differences between the pre-, post- and follow-up scores in three of the motivation subscales. The amotivation (i.e., lack of motivation) did not change significantly over time. The scores for attitude did not change significantly over time.

\subsection{Relationship of motivation and attitude change scores to goal implementation}

Eleven participants reported goals related to implementing evidenced-based strategies in their teaching and nine of them reported achieving one of more of their goals at the three-month follow-up period. Because of the unequal and small sample size, there was significant risk for violating the assumption of normality of data for t-tests. However, the data did not show skewness or kurtosis, and variances for each of the two groups (implementers and non-implementers) were similar (i.e., ranged from .43 to 1.88 ) for each of the scores, indicating that it was reasonable to use $t$-tests ${ }^{\text {[24] }}$. Table 3 illustrates the t-test results examining the differences between nine faculty who did ("Yes") and two faculty did not ("No") implement a teaching goal based on evidence in terms of their motivation subscale and attitude total scores obtained at follow-up. There was a significant difference in the external regulation score comparing faculty subgroups (i.e., implementers versus non-implementers). 
The barriers to implementation identified by the two participants who did not progress to implementation were lack of resources to support the search for best practice in nursing education, "old books" in libraries, lack of access to current journals with research, and limited access to the internet or computers. Additional barriers listed were large numbers of students and time constraints.

Table 1. Demographic characteristics of the study participants $(n=48)$

\begin{tabular}{lll}
\hline Variable & Frequency & Percent \\
\hline Age (years) & 29 & $60.4 \%$ \\
$<30$ & 15 & $31.3 \%$ \\
30 - 40 & 4 & $8.3 \%$ \\
$>40$ & $29.75 \pm 6.50$ & \\
Mean \pm standard deviation & & \\
Years of experience In academic settings & $5.52 \pm 4.98$ & \\
$\quad$ Mean \pm standard deviation & & \\
Years of experience in hospitals & $2.18 \pm 3.36$ & \\
$\quad$ Mean \pm standard deviation & & $100 \%$ \\
Gender & 48 & $50.0 \%$ \\
Female & & $27.1 \%$ \\
Educational Qualification & 24 & $20.8 \%$ \\
Bachelor & 13 & $2.1 \%$ \\
Master & 10 & \\
Doctorate & 1 & $50.0 \%$ \\
Other (Assistant professor) & & $27.1 \%$ \\
Academic ranking & 24 & $20.8 \%$ \\
Demonstrator & 13 & $2.1 \%$ \\
Assistant lecturer & 10 & $14.6 \%$ \\
Lecturer & 1 & $22.9 \%$ \\
Assistant professor & & $8.3 \%$ \\
Specialty & 7 & $18.8 \%$ \\
Nursing administration & 11 & $14.6 \%$ \\
Medical-Surgical nursing & 4 & $20.8 \%$ \\
Pediatric nursing & 9 & \\
Psychiatric nursing & 7 & \\
Gynecology \&Obstetric nursing & 10 & \\
Community health nursing & & \\
\hline
\end{tabular}

Table 2. Mean scores of motivation and attitude of nurse educators about evidence-based teaching before, immediately and after three months of participation in the workshop

\begin{tabular}{lcccll}
\hline Items & $\begin{array}{l}\text { Pre }(\mathbf{n}=\mathbf{4 8}) \\
\text { Mean } \pm \text { SD }\end{array}$ & $\begin{array}{l}\text { Post }(\mathbf{n}=\mathbf{4 8}) \\
\text { Mean } \pm \text { SD }\end{array}$ & $\begin{array}{l}\text { Follow-Up(n= 40 }) \\
\text { Mean } \pm \text { SD }\end{array}$ & F & P value \\
\hline $\begin{array}{l}\text { Motivation } \\
\begin{array}{l}\text { Intrinsic } \\
\text { motivation }\end{array}\end{array}$ & $19.05 \pm 5.12$ & $21.60 \pm 4.78$ & $21.87 \pm 4.18$ & 5.58 & .005 \\
$\begin{array}{l}\text { External } \\
\text { regulation }\end{array}$ & $14.22 \pm 5.54$ & $14.82 \pm 5.76$ & $17.87 \pm 6.32$ & 5.30 & .007 \\
$\begin{array}{l}\text { Identified } \\
\text { regulation }\end{array}$ & $20.05 \pm 5.60$ & $22.02 \pm 5.09$ & $23.80 \pm 3.93$ & 7.78 & .001 \\
Amotivation & $17.35 \pm 2.65$ & $16.00 \pm 2.26$ & $17.05 \pm 2.40$ & 3.00 & .055 \\
Attitude & $60.50 \pm 7.86$ & $61.85 \pm 6.75$ & $60.62 \pm 7.82$ & .49 & .611 \\
\hline
\end{tabular}


Table 3. Mean scores of motivation, attitude, and implementation of personal goals among nurse educators after three months of participation in the workshop

\begin{tabular}{|c|c|c|c|c|}
\hline \multirow[b]{2}{*}{ Items } & \multicolumn{2}{|c|}{ Goal Implementation } & \multirow[b]{2}{*}{ t-test } & \multirow[b]{2}{*}{$P$ Value } \\
\hline & $\begin{array}{l}\text { Yes } \quad(n=9) \\
\text { Mean } \pm \text { SD }\end{array}$ & $\begin{array}{l}\text { No } \quad(n=2) \\
\text { Mean } \pm \text { SD }\end{array}$ & & \\
\hline \multicolumn{5}{|l|}{ Motivation } \\
\hline Intrinsic motivation & $22.11 \pm 2.66$ & $23.50 \pm 4.94$ & .591 & .569 \\
\hline Identified regulation & $23.88 \pm 3.21$ & $27.00 \pm 1.41$ & 1.29 & .227 \\
\hline External regulation & $15.88 \pm 5.23$ & $25.50 \pm 3.53$ & 2.42 & $.038 *$ \\
\hline Lack of motivation & $17.33 \pm 2.64$ & $17.50 \pm 2.12$ & .082 & .936 \\
\hline Attitude & $71.00 \pm 5.65$ & $61.55 \pm 9.77$ & 1.28 & .231 \\
\hline
\end{tabular}

Note. $\mathrm{SD}=$ standard Deviation

\subsection{Additional analyses}

Data were examined for associations between change scores for each of the motivation subscales and change score for attitude using Pearson's correlation. The correlations are detailed in Table 4 with three items demonstrating significant correlation at follow-up. Specifically, change in attitude was correlated with change scores in lack of motivation, identified regulation, and external regulation. Change scores were calculated as baseline minus immediate and baseline minus three-month post-workshop scores. The association was negative between identified regulation and attitude and positive for the other two scores; all of these associations were of moderate strength.

Table 4. Correlation between changes in measures of motivation and attitude of nurse educators about evidence-based teaching immediately and after three months of participation in the workshop

\begin{tabular}{|c|c|c|c|c|}
\hline \multirow{2}{*}{ Items } & \multicolumn{2}{|c|}{$\begin{array}{l}\text { Attitude Change scores immediately } \\
\text { after workshop }\end{array}$} & \multicolumn{2}{|c|}{$\begin{array}{l}\text { Attitude Change scores three months after } \\
\text { workshop }\end{array}$} \\
\hline & $r$ & $p$ value & $r$ & $p$ value \\
\hline \multicolumn{5}{|c|}{ Motivation change scores immediately following workshop } \\
\hline Intrinsic motivation & -.00 & .96 & -.07 & .65 \\
\hline Identified regulation & .12 & .39 & -.06 & .68 \\
\hline External regulation & .13 & .37 & .23 & .13 \\
\hline Lack of motivation & -.09 & .53 & .08 & .60 \\
\hline \multicolumn{5}{|c|}{ Motivation change scores three months after workshop } \\
\hline Intrinsic motivation & .19 & .24 & -.24 & .13 \\
\hline Identified regulation & .09 & .55 & -.37 & $.01^{*}$ \\
\hline External regulation & .16 & .30 & .57 & $.00^{* *}$ \\
\hline Lack of motivation & .00 & .97 & .35 & $.02 *$ \\
\hline
\end{tabular}

* Correlation is significant at 0.05 levels (2-tailed)

Relationships between the participant characteristics of age, years of teaching experience, and years of hospital experience and the motivational and attitude scores at each time point using Pearson's were also examined. No correlations were demonstrated. The association between education preparation and scores were examined using Chi square and no associations were found. 


\section{Discussion}

This interventional study examined the motivation and attitude toward evidence-based nursing education in faculty teaching at Zagazig University and nearby schools of nursing in northeast Egypt. Significant increases in intrinsic motivation, identified regulation, and external regulation occurred at both time periods following our workshop with the highest scores occurring three months after the workshop. Amotivation was initially moderate and did not change over time. Based on the SDT model, the subscale scores indicated a mix of intrinsic and extrinsic motivations were present at baseline and this finding is similar to one other study in non-nurse educators ${ }^{[25]}$. Our results support expert opinion that providing an opportunity to examine educational research and apply it to a course or curriculum is an important step in using evidence in teaching.

Positive attitude toward evidence-based teaching practice was present initially and did not change over time. One explanation for this finding is that attitude was already very positive prior to the workshop; a workshop may not be the ideal venue to create incremental gains once a high positive attitude is demonstrated. We cannot be sure that the scores of our participants showed a "ceiling effect". It may be that the immediate post-workshop and three month time points for measurement were not enough time to demonstrate change in attitude. Unlike our study, one study reported an increase in attitude following an educational intervention. Using a different measure, clinical physician educators demonstrated an increase in attitude toward evidence-base approaches to practice after a workshop on evidence-based skills ${ }^{[26]}$. In regards to the second research question, only external regulation at follow-up demonstrated a significant difference in whether goal implementation occurred. The data indicate low external regulation (i.e., scores of 15.88//28) was more likely to result in implementing a goal related to evidence-based teaching practices. However, given the sample size of 11 and unequal distribution between implementers and non-implementers, these data need to be interpreted cautiously. As pilot data, there is an inference that external motivators do not result in adoption of evidence-based practices in nursing education.

Barriers to implementing a goal that encompassed an evidence-based teaching strategy were similar to reports in the literature about adopting evidence in clinical practice and in nursing education ${ }^{[7,27-29]}$. Both participants who identified barriers were at the demonstrator level, somewhat similar to the MSN-prepared clinical faculty at an instructor level in U.S. academia and at this level neither the skill set nor knowledge base builds an expectation to develop new strategies based on evidence.

Prior to the workshop, participants scored highest in the motivational subscales of identified regulation (20.05/28) and intrinsic motivation (19.05/28). A relatively high score in identified regulation indicated workshop attendees were motivated to perform evidence-based teaching behaviors because participation was congruent with a self-perceived benefit and was important for their personal growth and. The similar score in intrinsic motivation indicated attendees had a significant degree of self-determination related to use of evidence-based nursing education strategies. However, neither score was extremely high (e.g., > 90\% or $>25 / 28$ ) at any time point and this may explain the subsequent finding of why the majority of attendees did not report actions related to adoption of evidence-based teaching at three months after the workshop.

The moderate score in external regulation (14.22/28) at baseline suggested that evidence-based teaching behaviors were not perceived to be initiated and maintained by forces outside of the self ${ }^{[30]}$. Over time, the positive motivation scores increased significantly. Since Zagazig University sponsored the workshop and provided work release time to attend, it is not surprising that external factors were perceived as "moderate" motivators in this sample. The increase in perception of external forces influencing evidence-based practice may indicate a change in the University culture, with increased perception of rewards for adopting evidence-based teaching strategies occurring at three months following the workshop.

The moderate scores in amotivation indicate that there is a lack of motivation in this sample that may lead to a failure to act. Amotivation may reflect a belief that there is no relationship between educational strategies and outcomes such as 
personal growth, job recognition, or student achievement in nursing education ${ }^{[20]}$. The moderate scores in amotivation may explain the reduced participation at follow-up. If attendees were not motivated to adopt evidence-based teaching practices, then perhaps they also did not value participating in this study, contributing to a low follow-up response at three months.

The greatest increases in the subscale scores occurred three months after the workshop. While it is unclear if the relatively modest increment in intrinsic motivation, identified regulation and external regulation are important to the performance of teaching, it is reassuring to know that gains in motivation subscales were sustained or greater over time. Our findings of sustained motivation differ from reports in the literature. For example, three studies show a small increase in motivational scores among counselors after a workshop for evidence-based treatment but that the scores quickly reverted to pre-workshop levels ${ }^{[31-33]}$. We are not sure why 29 participants left one item blank when asked whether they were implementing a teaching goal reflecting an evidence-based strategy. It may be that workshop participants thought that they were already performing well in terms of incorporating best practices in their course and curriculum so there was no need to respond to this question. During the workshop, several participants showed the speakers examples of case studies and simulation checklists that embraced the content of the workshop. Alternatively, the majority of participants were junior faulty, ranked at the demonstrator level, and they are not involved in designing course changes. Perhaps junior faculty did not feel it was appropriate to generate goals or evaluate progress toward a goal for course or curriculum changes.

There were only two significant positive correlations between changes in measures of external regulation and amotivation with nurse educators attitude scores three months after the workshop providing limited support to relationships described in the Theory of Planned Behavior model. A low score in identified regulation was moderately, negatively associated with a high/positive attitude and does not support the model. In a study examining inter-professional education in health care, the attitudinal scores increased over time with multiple workshops ${ }^{[34]}$. In a study of clinical nurses, educational strategies to introduce evidence for dementia care showed no change in attitude toward research or the potential to use research findings ${ }^{[35]}$. Perhaps, in our study, participants who had a positive attitude toward evidenced-based teaching practices did not internalize the external rewards (low self-regulation scores) because the external rewards were new. Additional time may be needed to move perception of external rewards into identified regulation. This interpretation is supported by the increase in external regulation over time (see Table 2).

Additional results supported no relationships between participant characteristics and either motivation subscales or attitude toward evidence-based teaching. These findings are similar to Bennett ${ }^{[36]}$ who found that the age of University lecturers did not correlate significantly with their attitudes toward use of new teaching methods ${ }^{[36]}$. Abu Qudais and colleagues ${ }^{[37]}$ also reported no significant differences in senior faculty members attitudes toward using information and communication technology related to their years of experience ${ }^{[37]}$. Salbach and colleagues ${ }^{[38]}$ found that positive attitudes of clinicians toward using evidence in practice were associated with more education ${ }^{[38]}$. However, this last study is not specific to nurse educators and the difference in samples could account for the differences in findings.

\subsection{Limitations of the study}

The use of a convenience sample limits the generalizability of the study but the high consent rate provides confidence that results are representative to this setting. Because a minority of participants reported setting a goal, the results linking external regulation with goal implementation for adopting evidence-base strategies should be considered pilot or preliminary. While this is a single site study, it does support that an evidence-based approach to nursing education is being examined worldwide and that nurse educators in northeast Egypt are motivated to use evidence in the education of their students

\subsection{I mplications for nursing educators}

A workshop was useful to develop skills and influence factors that contribute to adopting research-based strategies in nursing education as suggested by nurse leaders ${ }^{[31]}$. Our sample reported increased and sustained intrinsic and extrinsic 
motivation following a workshop on best practices in nursing education. After the workshop, $23 \%$ of participants applied evidence to a teaching strategy within three months. Additional opportunity to develop and test goals related to implementing evidence-based educational strategies are recommended to help translate motivation and positive attitude into action. Future studies should link faculty attributes with student outcomes-does motivation or a positive attitude toward adopting evidence-based teaching strategies translate to improved student achievement?

\section{Conclusion}

This is the first study, to our knowledge, examining the personal factors in an Egyptian nursing faculty contributing to adopting evidence-based nursing education strategies. A positive attitude and moderate-to-high motivation toward using evidence to teach nursing were found in this study. A workshop about best practices in nursing education fostered increased intrinsic motivation, identified regulation, and external regulation immediately and changes were sustained over a three month period. The positive attitude toward evidence-based nursing education is this sample is a welcome finding. A total of $23 \%$ of workshop participants implemented an evidence-based education strategy after the workshop, promoting best practices in nursing education. This report reflects a shared goal of optimizing nursing education as a worldwide endeavor.

\section{References}

[1] Oermann MH. Evidence-based programs and teaching/evaluation methods: Needed to achieve excellence in nursing education. In Adams MH, Valiga TM (Eds.). Achieving Excellence in Nursing Education. National League for Nursing, New York. 2009; 63-76.

[2] Ferguson L, Day RA. Evidence-based nursing education: myth or reality? J Nurs Educ. 2009; 44: 107-115.

[3] MacIntyre RC, Murray TA, Teel CS, Karshmer JF. Five recommendations for prelicensure clinical nursing education. J Nurs Educ. 2009; 48: 447-453. PMid:19681534 http://dx.doi.org/10.3928/01484834-20090717-03

[4] Emerson RJ, Records K .Today's challenge, tomorrow's excellence: the practice of evidence-based education. J Nurs Educ. 2008; 47: 359-370. http://dx.doi.org/10.3928/01484834-20080801-04

[5] Seropian MA, Brown K, Gavilanes JS, Driggers B. Simulation: not just a manikin. J Nurs Educ. 2004; 43: $164-169$. PMid:15098910

[6] Schunk DH, Pintrich PR, Meece JL. Motivation in Education: Theory, Research, and Application. Pearson Prentice-Hall, Upper Saddle River, New Jersey. 2008.

[7] Stichler JF, Fields W, Kim SC, Brown CE. Faculty knowledge, attitudes, and perceived barriers to teaching evidence-based nursing. J Prof Nurs. 2011; 27: 92-100. PMid:21420041 http://dx.doi.org/10.1016/j.profnurs.2010.09.012

[8] Adams MH, Valiga TM. Achieving Excellence in Nursing Education. National League for Nursing, New York. 2009.

[9] Benner P, Sutphen M, Leonard B, Day L. Educating Nurises: A Call for Radical Transformation. Jossey-Boss, San Francisco, CA. 2009

[10] Medley CF, Horne C. Using simulation technology for undergraduate nursing education. J Nurs Educ. 2005 ; 44: 31-34. PMid:15673172

[11] Greer AG, Pokorny M, Clay MC, Brown S, Steele LL. Learner-centered characteristics of nurse educators. Int J Nurs Educ Scholarsh. 2010; 7, Article6 (epub).

[12] Rossetti J, Fox PG. Factors related to successful teaching by outstanding professors: an interpretive study. J Nurs Educ. 2009; 48: 11-16. http://dx.doi.org/10.3928/01484834-20090101-09

[13] Ajzen I. The theory of planned behavior. Organizational Behavior and Human Decision Processes. 1991; 50, $179-211$. http://dx.doi.org/10.1016/0749-5978(91)90020-T

[14] Riggs CJ. Taming the pedagogy dragon. J Contin Educ Nurs. 2010; 41: 388-389. PMid:20839732 http://dx.doi.org/10.3928/00220124-20100825-02

[15] Brown ST, Kirkpatrick MK, Greer A ,Matthias AD, Swanson MS. The use of innovative pedagogies in nursing education: an international perspective. Nurs Educ Perspect. 2009; 30: 153-158. PMid:19606657

[16] Ajzen I. Nature and operation of attitudes. Annu Rev Psychol. 2001; 27: 52-58. 
[17] Ajzen I. The theory of planned behaviour: reactions and reflections. Psychol Health. 2011; 26: 1113-1127. PMid:21929476 http://dx.doi.org/10.1080/08870446.2011.613995

[18] Lechuga VM, Lechuga DC. Faculty motivation and scholarly work: Self-determination and self-regulation prespectives. The Journal of Professoriate. 2012; 2.

[19] Deci EL, Ryan RM. Handbook of Self-Determination Research. University of Rochester Press, Rochester NY. 2002.

[20] Ryan RM, Deci EL. An overview of self-determination theory: An organismic-dialectical perspective. In Ryan RM, Deci EL (Eds.). Handbook of Self-Determination Research. University of Rochester Press, Rachester NY, 2002: 3-33.

[21] Guay F, Vallerand RJ, Balanchard C. On the assessment of situational and extrinsic motivation: The Situational Motivation Scalse (SIMS). Motivation and Emotion. 2000; 24: 175-213. http://dx.doi.org/10.1023/A:1005614228250

[22] Ruzafa-Martinez M, Lopez-Iborra L, Madrigal-Torres M. Attitude towards Evidence-Based Nursing Questionnaire: development and psychometric testing in Spanish community nurses. J Eval Clin Pract. 2011; 17: 664-670. PMid:21504516 http://dx.doi.org/10.1111/j.1365-2753.2011.01677.x

[23] da Costa Santos CM, de Mattos Pimenta CA, Nobre MR . The PICO strategy for the research question construction and evidence search. Rev Lat Am Enfermagem. 2007; 15: 508-511. PMid:17653438 http://dx.doi.org/10.1590/S0104-11692007000300023

[24] Corty EW. Using and Interpreting Statistics: A Practical Text for the Health, Behavioral, and Social Sciences. Mosby, St. Louis. 2007.

[25] Bassi M, Delle Fave A. Optimal experience among teachers: new insights into the work paradox. J Psychol. 2012; 146 : 533-557. http://dx.doi.org/10.1080/00223980.2012.656156

[26] Kouhpayehzadeh J, Baradaran H, Arabshahi KS, Knill-Jones R. Clinical teachers' attitudes toward the efficacy of evidence-based medicine workshop and self-reported ability in evidence-based practice in Iran. J Contin Educ Health Prof. 2006; 26: 210-14. PMid:16986146 http://dx.doi.org/10.1002/chp.72

[27] Hannes K, Vandersmissen J, De Blaeser L, Peeters G, Goedhuys J, Aertgeerts B. Barriers to evidence-based nursing: a focus group study. J Adv Nurs. 2007; 60: 162-171. PMid:17877563 http://dx.doi.org/10.1111/j.1365-2648.2007.04389.x

[28] Schoonover H. Barriers to research utilization among registered nurses practicing in a community hospital. J Nurses Staff Dev. 2009; 25: 199-212. PMid:19657252 http://dx.doi.org/10.1097/NND.0b013e3181ae145f

[29] Strickland RJ, O'Leary-Kelley C. Clinical nurse educators' perceptions of research utilization :barriers and facilitators to change. J Nurses Staff Dev. 2009; 25: 164-171; quiz 172-163.

[30] Vansteenkiste M, Ryan RM, Deci EL. Self-determination theory and the explanatory role of psychological needs in human well-being. In Bruni L, Comin F, Pugno M (Eds.). Capabilites and Happiness. Oxford University Press, Oxford UK. 2008; 187-223.

[31] Baer JS, Rosengren DB, Dunn CW, Wells EA, Ogle RL, Hartzler B. An evaluation of workshop training in motivational interviewing for addiction and mental health clinicians. Drug Alcohol Depend. 2004; 73: 99-106. PMid:14687964 http://dx.doi.org/10.1016/j.drugalcdep.2003.10.001

[32] Miller WR, Yahne CE, Moyers TB, Martinez J, Pirritano M. A randomized trial of methods to help clinicians learn motivational interviewing. J Consult Clin Psychol. 2004; 72: 1050-1062. PMid:15612851 http://dx.doi.org/10.1037/0022-006X.72.6.1050

[33] Mitcheson L, Bhavsar K, McCambridge J. Randomized trial of training and supervision in motivational interviewing with adolescent drug treatment practitioners. J Subst Abuse Treat. 2009; 37: 3-8. PMid:19150203 http://dx.doi.org/10.1016/j.jsat.2008.11.001

[34] Clark PG. Examining the interface between interprofessional practice and education: lessons learned from Norway for promoting teamwork. J Interprof Care. 2011; 25: 26-32. PMid:20795829 http://dx.doi.org/10.3109/13561820.2010.497751

[35] Henderson A, Winch S, Holzhauser K, De Vries S. The motivation of health professionals to explore research evidence in their practice: An intervention study. J Clin Nurs. 2006; 15: 1555-64. PMid:17118078 http://dx.doi.org/10.1111/j.1365-2702.2006.01637.x

[36] Bennett R. Lecturer's altitudes towards new teaching methods. In The International Journal of Management Education. Emerald City. 2001; 42-52.

[37] Abu Qudais M, Al-Adaileh M, Al-Omari A. Senior faculty members' attitudes in Jordanian universities towards using information and communication technology. International Arab Journal of e-Technology. 2010; 1: 135-141.

[38] Salbach NM, Jaglal SB, Korner-Bitensky N, Rappolt S, Davis D. Practitioner and organizational barriers to evidence-based practice of physical therapists for people with stroke. Phys Ther. 2007; 87: 1284-1303. PMid:17684088 http://dx.doi.org/10.2522/ptj.20070040 